\title{
Humoral and cellular immune responses to the fimbriae of Porphyromonas gingivalis and their synthetic peptides
}

\author{
T. OGAWA, H. OGO, H. UCHIDA and S. HAMADA \\ Department of Oral Microbiology, Osaka University Faculty of Dentistry, Yamadaoka, Suita-Osaka, 565 Japan
}

\begin{abstract}
Summary. Subcutaneous injection of fimbriae from Porphyromonas gingivalis strain 381 in Freund's incomplete adjuvant (FIA) resulted in an excellent serum anti-fimbrial immunoglobulin $\mathrm{G}(\mathrm{IgG})$ response in guinea-pigs and BALB/c mice. Administration of $P$. gingivalis fimbriae also elicited distinct cellular immune responses to the fimbriae in terms of ear lobe reaction in BALB/c but not in BALB/c $n u / n u$ mice, and of skin reaction in guineapigs. When the guinea-pigs were given a semi-synthetic adjuvant GM-53-sodium $\beta$ - $N$-acetylglycosaminyl-(1 $\rightarrow 4$ )- $N$-acetylmuramyl-L-alanyl-D-isoglutaminyl-(L)-stearoyl-(D)meso-2, 6-diaminopimelic acid-(D)-amide-D-alanine-and fimbriae in FIA by subcutaneous injection, more enhanced production of serum anti-fimbrial IgG and stronger cellular immune responses were induced in the guinea-pigs than in those given fimbriae alone. Synthetic peptide FP381(202-221), which corresponds to the amino-acid residue numbers 202-221 based on the amino-acid sequence of fimbrilin from $P$. gingivalis strain 381, elicited humoral and cellular immune responses in guinea-pigs immunised with the fimbriae or FP381(202-221). Furthermore, subcutaneous administration of synthetic peptide FP381(6180 ) with GM- 53 induced lesser degrees of humoral and cellular immune responses in guineapigs than did FP381(202-221). However, when the fimbriae or FP381(61-80) were administered with bovine serum albumin (BSA), markedly elevated levels of specific anti-BSA antibody were seen in the serum of BALB/c mice. These results clearly indicated that fimbriae from $P$. gingivalis 381 and their oligopeptide segments induced humoral and cellular immune responses and exhibited immuno-adjuvant activities in guinea-pigs and $B A L B / c$ mice.
\end{abstract}

\section{Introduction}

Porphyromonas gingivalis is a gram-negative, blackpigmented anaerobic bacterium that has been associated with the development of chronic periodontal diseases in man. ${ }^{1}$ Antigen-specific antibodies to the surface components of $\boldsymbol{P}$. gingivalis have been detected in the serum and crevicular fluid of patients with periodontal diseases. ${ }^{2-6}$ Among these components, the fimbriae of $P$. gingivalis have been presumed to be important for the adherence of the organisms to host cells. ${ }^{7-8}$ We have shown previously that $P$. gingivalis fimbria-specific antibody-secreting cells are increased in the inflamed gingival tissues of patients with periodontal diseases, and antigen-specific antibodies are present in their serum. ${ }^{9}$ It has been shown also that subcutaneous or oral immunisation with $P$. gingivalis fimbriae in BALB/c mice induces markedly increased levels of fimbria-specific IgA or IgG antibodies, or both, in saliva and serum, and fimbria-specific antibody-producing cells have been detected in various lymphoid tissues. ${ }^{10,11}$

Fimbriae from $P$. gingivalis strain 381 and their synthetic peptide segments are known to have multi-

Received 21 Sept. 1993; revised version accepted 21 Dec. 1993. functional properties such as antigenicity, haemagglutinating activity, mitogenic and polyclonal B-cell activation (PBA) activity for mouse splenocytes and induction of production of cytokines such as tumour necrosis factor-alpha (TNF- $\alpha$ ) and interleukin-6 (IL6 ) in human monocyte/macrophage cultures. ${ }^{12}$ The present study was designed to determine if $P$. gingivalis fimbriae and their synthetic peptide segments known to exert various immunobiological effects in a host would induce humoral and cellular immune responses and exhibit immuno-adjuvanticity in guinea-pigs and mice.

\section{Materials and methods}

\section{Animals}

Male BALB/c and BALB/c $n u / n u$ mice ( 8 weeks old) were obtained from Japan SLC, Inc., Hamamatsu, Japan. Closed-colony male albino guinea-pigs (weight 300-350 g) were purchased from Nihon Rabbit Inc., Osaka, Japan.

\section{Preparation of fimbriae from P. gingivalis 381}

$P$. gingivalis strain 381 was grown anaerobically in GAM broth (Nissui, Tokyo, Japan) supplemented 
with haemin and menadione for $26 \mathrm{~h}$ at $37^{\circ} \mathrm{C}$, and its fimbriae were isolated as described previously. ${ }^{10}$ No contaminating proteins were detected by SDS-PAGE, and the subunit structure of fimbriae, fimbrilin, was identified as a single band of the $41-\mathrm{kDa}$ subunit protein. $^{10}$

\section{Synthesis of peptide}

Peptides FP381(61-80), whose amino-acid sequence is GKTLAEVKALTTELTAENQE, and FP381(202221), which corresponds to VAPAADAPQGFTVLENDYSA, based on the amino-acid sequence of the native fimbrilin of $P$. gingivalis 381 derived from the nucleotide sequence, ${ }^{13}$ were synthesised with a model 9050 peptide synthesiser (Japan Millipore Ltd, Tokyo) by the solid-phase methods. ${ }^{14}$ After cleavage of the protecting groups with trifluoroacetic acid: $m$-cresol: ethanedithiol:methanesulphonic acid (90:2 $5: 5: 2 \cdot 5)$, the peptide was purified by high performance liquid chromatography on a reversed phase column (Capcell Pak C18 SG120, 1.5 × $15 \mathrm{~cm}$; Shiseido, Tokyo) with a linear gradient $(6-60 \%)$ of acetonitrile in acetic acid $0.1 \%$ at a flow rate of $23 \mathrm{ml} / \mathrm{min}$. The major peak fraction of the peptide was collected by monitoring the absorbance at $220 \mathrm{~nm}$. The purified peptide synthesised was analysed for composition by quantitative amino-acid analysis and sequenced by automated Edman degradation with a model $6400 / 6600$ protein sequencer (Japan Millipore Ltd).

\section{Adjuvant}

Muramyldipeptide (MDP) and sodium $\beta$ - $N$-acetylglucosaminyl-(1 $\rightarrow 4)-N$-acetylmuramyl-L-alanyl-D-isoglutaminyl-(L)-stearoyl-(D)-meso-2, 6-diaminopimelic acid-(D)-amide-D-alanine (GM-53) ${ }^{\mathbf{1 5}}$ were generously supplied by Daiichi Seiyaku Co., Tokyo and Dainippon Pharmaceutical Co., Osaka, respectively. Freund's incomplete adjuvant (FIA) was purchased from Difco.

\section{Assay for humoral and cellular immune responses}

Groups of six guinea-pigs were given various doses of fimbriae on their synthetic peptides by injection into the left hind footpad with or without a dose of adjuvant GM-53 in FIA on day 0. Skin tests were performed to evaluate the induction of a cellular immune response to fimbrial antigen or the synthetic peptide segments of the fimbriae. ${ }^{16}$ Briefly, the immunised guinea-pigs were given either an intracutaneous injection of $100 \mu \mathrm{g}$ of fimbriae or of their synthetic peptide segments 35 days after immunisation. The skin test was examined for the extent and degree of redness, swelling and necrosis $48 \mathrm{~h}$ after the intradermal provocative injection. Serum specimens were taken 1 day after the skin test and stored at $-80^{\circ} \mathrm{C}$ until assayed. The immunoglobulin $\mathrm{G}$ (IgG) levels of antigen-specific antibodies in the serum of the guinea-pigs were determined by an ELISA technique. ${ }^{10}$ The individual values are expressed as points and the bars indicate the median values.

In some experiments, groups of $10 \mathrm{BALB} / \mathrm{c}$ and $\mathrm{BALB} / \mathrm{c} n u / n u$ mice were given $100 \mu \mathrm{g}$ of the fimbriae in FIA by subcutaneous injection on days 0 and 28 . On day 33 these mice were given $10 \mu \mathrm{g}$ of the fimbriae by intracutaneous injection into the ear lobe, whose thickness at the injection site was measured daily for 3 days with a dial gauge (Model G; Ozaki Corp., Tokyo). Serum specimens were taken 1 day after the ear lobe test. Antigen-specific IgG levels were determined by ELISA. ${ }^{10}$

\section{Immuno-adjuvant activity in mice}

BALB/c mice (10/group) were immunised by subcutaneous injection of $100 \mu \mathrm{g}$ of bovine serum albumin (BSA; Sigma) with or without $100 \mu \mathrm{g}$ of test specimen in PBS or FIA, or were given FIA alone, on days 0 and 28. Serum anti-BSA IgG antibody levels were determined by ELISA 5 days after the secondary immunisation.

\section{Statistical analysis}

The significance of differences between means of groups was determined by Student's $t$ test.

\section{Results}

Induction of humoral and cellular immune responses in guinea-pigs and $B A L B / c$ mice after immunisation with $P$. gingivalis fimbriae

Guinea-pigs immunised with $P$. gingivalis 381 fimbriae in FIA were found to have raised anti-fimbrial IgG antibody levels in their serum (fig. 1). Subcutaneous injection of $P$. gingivalis fimbriae in FIA resulted in a dose-dependent induction of serum antibody responses over a concentration range of $50-500 \mu \mathrm{g}$ of fimbriae/animal. The production of fimbria-specific IgG reached its maximum at $500 \mu \mathrm{g}$ and was reduced at $1000 \mu \mathrm{g} /$ animal. Furthermore, the addition of a semi-synthetic adjuvant, GM-53, a stearoyl derivative of the disaccharide tetrapeptide isolated from Lactobacillus plantarum cell walls, resulted in much higher levels of fimbria-specific IgG responses in serum (fig. 1). The greatest adjuvant effect was observed when GM-53 was given subcutaneously to guinea-pigs at the maximum dosage of $500 \mu \mathrm{g} /$ animal with an equal dose of fimbriae. On the other hand, whereas $P$. gingivalis fimbriae also induced antifimbrial IgG in serum after immunisation in BALB/c mice, the did not do so in BALB/c nu/nu mice (data not shown).

$P$. gingivalis fimbriae could induce a cellular immune response in guinea-pigs when administered subcutaneously with or without adjuvant GM-53 in FIA. Fig. 2 illustrates the skin reaction after intradermal 


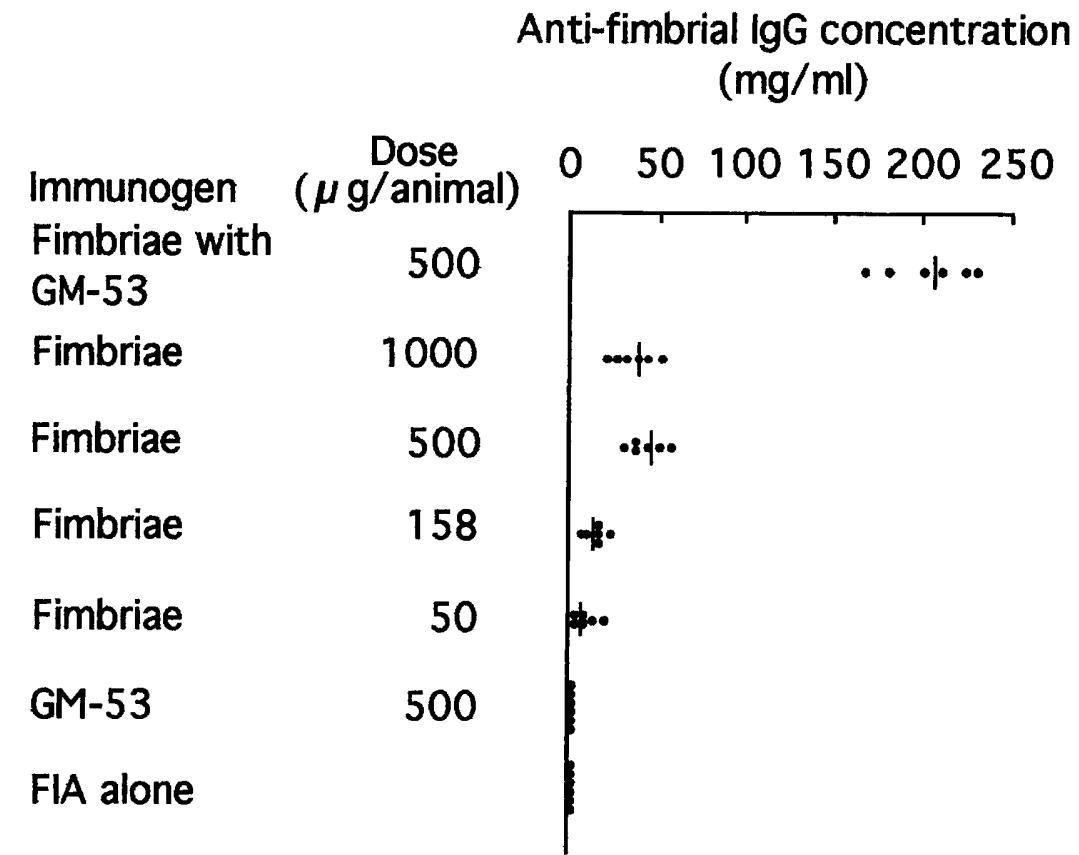

Fig. 1. Dose-response relationship between $P$. gingivalis fimbriae and serum IgG titres in guinea-pigs. Seven groups of six guinea-pigs were immunised subcutaneously with various doses of fimbriae with or without $500 \mu \mathrm{g}$ of GM-53 in FIA, with GM-53 in FIA or with FIA alone on day 0 . Serum anti-fimbrial IgG levels were determined by ELISA 1 day after skin test (on day 38). The individual values are expressed as points and the bar indicates the median value.

\begin{tabular}{|c|c|c|c|c|}
\hline \multirow{3}{*}{$\begin{array}{l}\text { Immunogen } \\
\text { Fimbriae with } \\
\text { GM-53 }\end{array}$} & \multirow[b]{2}{*}{$\begin{array}{c}\text { Dose } \\
\text { ( } \mu \mathrm{g} / \text { animal) }\end{array}$} & \multirow[b]{2}{*}{ Provocation } & \multicolumn{2}{|l|}{ Skin reaction } \\
\hline & & & $\begin{array}{cc} & \mathrm{mm}^{2} \\
0 & 100200300400\end{array}$ & necrosis \\
\hline & 500 & Fimbriae & -oppoo. & Yes \\
\hline Fimbriae & 1000 & Fimbriae & -ate & Yes \\
\hline Fimbriae & 500 & Fimbriae & oopon & Yes \\
\hline Fimbriae & 158 & Fimbriae & ato & Yes \\
\hline Fimbriae & 50 & Fimbriae & ه & No \\
\hline GM-53 & 500 & Fimbriae & & No \\
\hline FIA alone & & Fimbriae & & No \\
\hline
\end{tabular}

Fig. 2. Cellular immune responses induced by $P$. gingivalis fimbriae in seven groups of guinea-pigs (see fig. 1). Skin reaction was determined 35 days after immunisation. The individual values are expressed as points and the bar indicates the median value.

challenge of guinea-pigs immunised with fimbriae with or without GM-53 in FIA or FIA alone. A clear difference in the redness and swelling of the skin was noted between the immunised groups and the control group. $P$. gingivalis fimbriae were clearly found to induce a skin reaction in guinea-pigs and a linear dosereaction relationship was seen between the dose of fimbriae and the degree of this skin reaction and presence of necrosis (fig. 2). In animals given fimbriae together with adjuvant GM-53 $(500 \mu \mathrm{g})$ the swelling at the challenge site was more severe than in animals given an equal dose of fimbriae alone (fig. 2). On the other hand, whereas $P$. gingivalis fimbriae induced marked ear lobe reactions in BALB/c mice on intradermal challenge, they did not do so in BALB/c $n u / n u$ mice (fig. 3).

Induction of humoral and cellular immune responses in guinea-pigs after immunisation with synthetic peptide of fimbrilin

Synthetic peptide segments FP381(61-80) and FP381(202-221) were investigated for induction of humoral and cellular immune responses in guinea- 
a

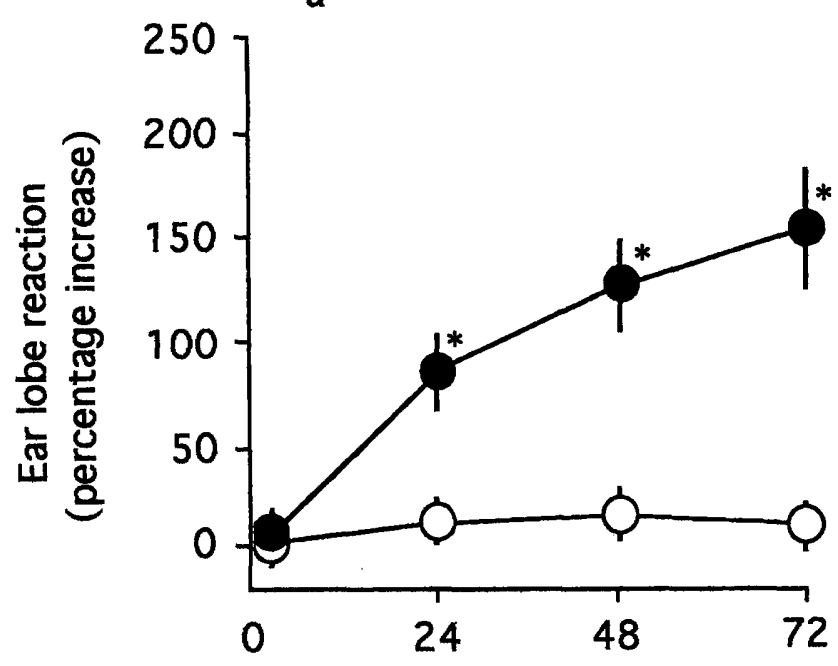

b

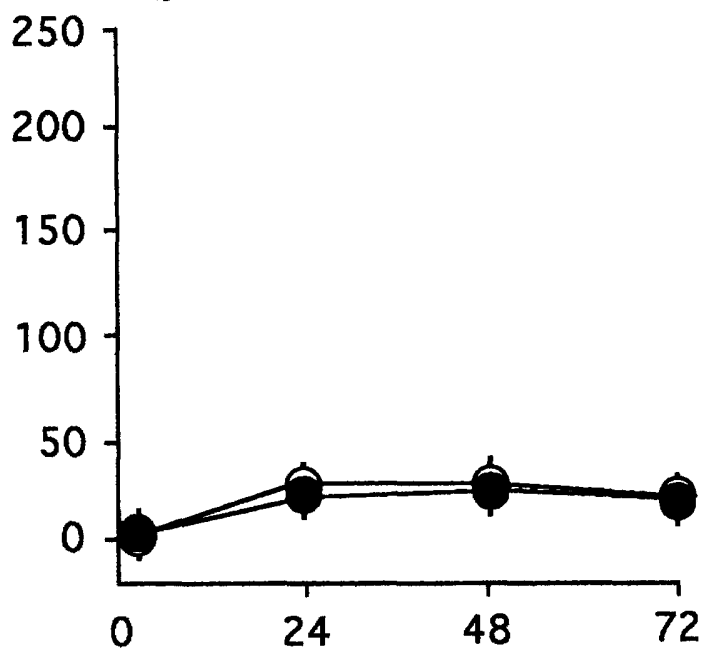

Time (h)

Fig. 3. The time course of the ear lobe reaction to fimbrial provocative injection in (a) BALB/c and (b) BALB/c nu/nu mice given $P$. gingivalis fimbriae in FIA (O) or FIA alone $(O)$. Results indicate ear lobe reaction after intracutaneous injection of $10 \mu \mathrm{l}$ of antigen solution (1 mg/ml). *Statistical difference from the value for the control (FIA alone) group, $\mathrm{p} \leqslant 0.01$.

\section{Serum IgG concentration $(\mu \mathrm{g} / \mathrm{ml})$ specific for}

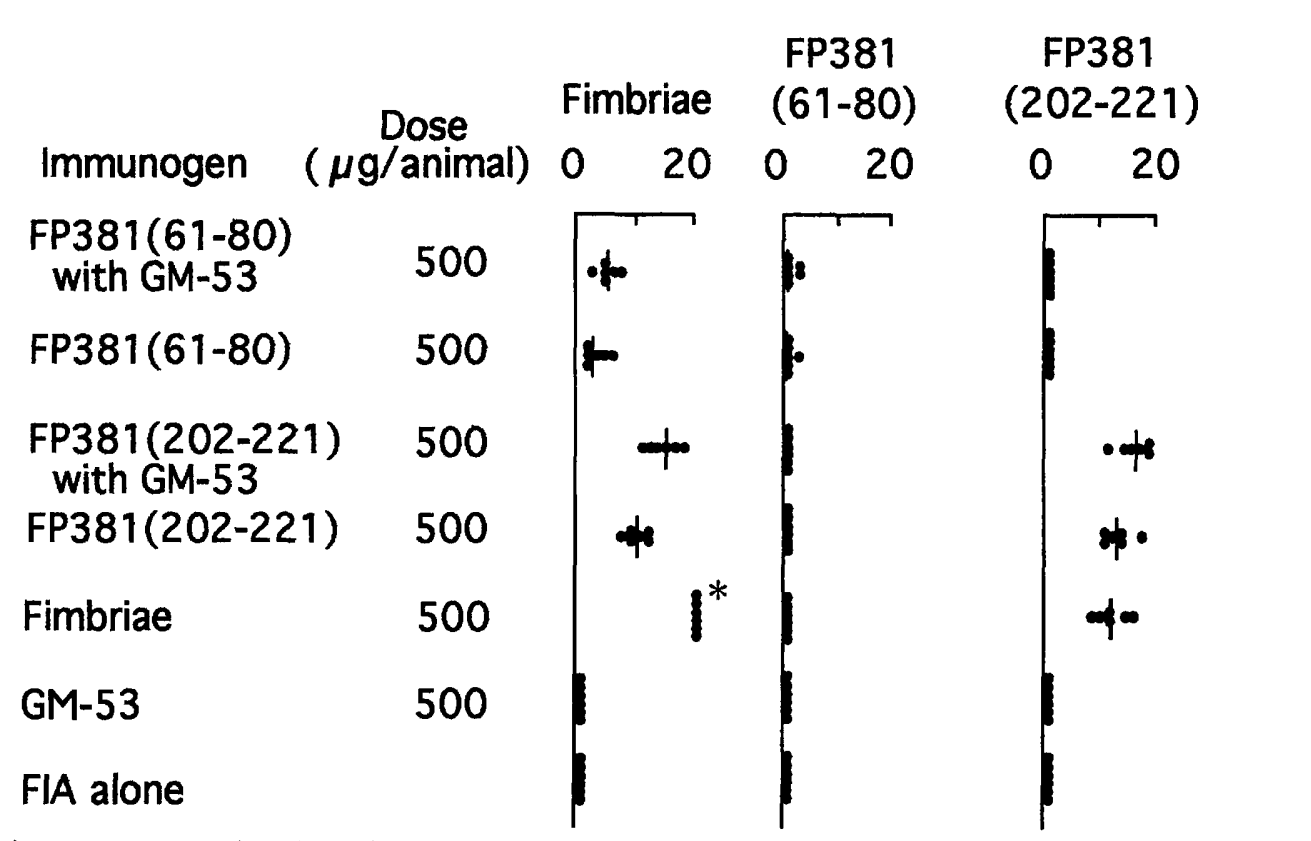

Fig. 4. Serum immune responses in guinea-pigs immunised with $P$. gingivalis fimbriae and their synthetic peptide segments (see fig. 1). The individual values are expressed as points and the bar indicates the median value. *Anti-fimbrial IgG concentration was $18.6 \mathrm{SE} 2 \cdot 0 \mathrm{mg} / \mathrm{ml}$.

pigs. Subcutaneous injection of FP381(61-80) or FP381(202-221) induced the production of antiFP381(61-80) or anti-FP381(202-221) IgG antibodies in the serum of guinea-pigs immunised with the synthetic peptide antigen with or without GM-53 in FIA (fig. 4). However, FP381(61-80) was far less effective than FP381(202-221) in inducing the production of serum antigen-specific IgG in guinea-pigs. Furthermore, FP381(202-221) but not FP381(61-80) reacted with the serum of the guinea-pigs immunised with $P$. gingivalis fimbriae in FIA, and similarly the fimbrial antigen reacted with serum IgG specific for FP381(202-221) (fig. 4).
FP381(61-80) did not elicit a significant skin reaction in guinea-pigs immunised with $P$. gingivalis fimbriae or FP381(61-80) in FIA, but did evoke a skin reaction when the peptide immunogen in FIA was combined with GM-53 (fig. 5).

\section{Adjuvant effect of $P$. gingivalis fimbriae and their synthetic peptide}

The table shows that $P$. gingivalis fimbriae and FP381(61-80) increased the production of anti-BSA IgG when $\mathrm{BALB} / \mathrm{c}$ mice were inoculated with BSA and with fimbriae or with FP381(61-80) in PBS or 


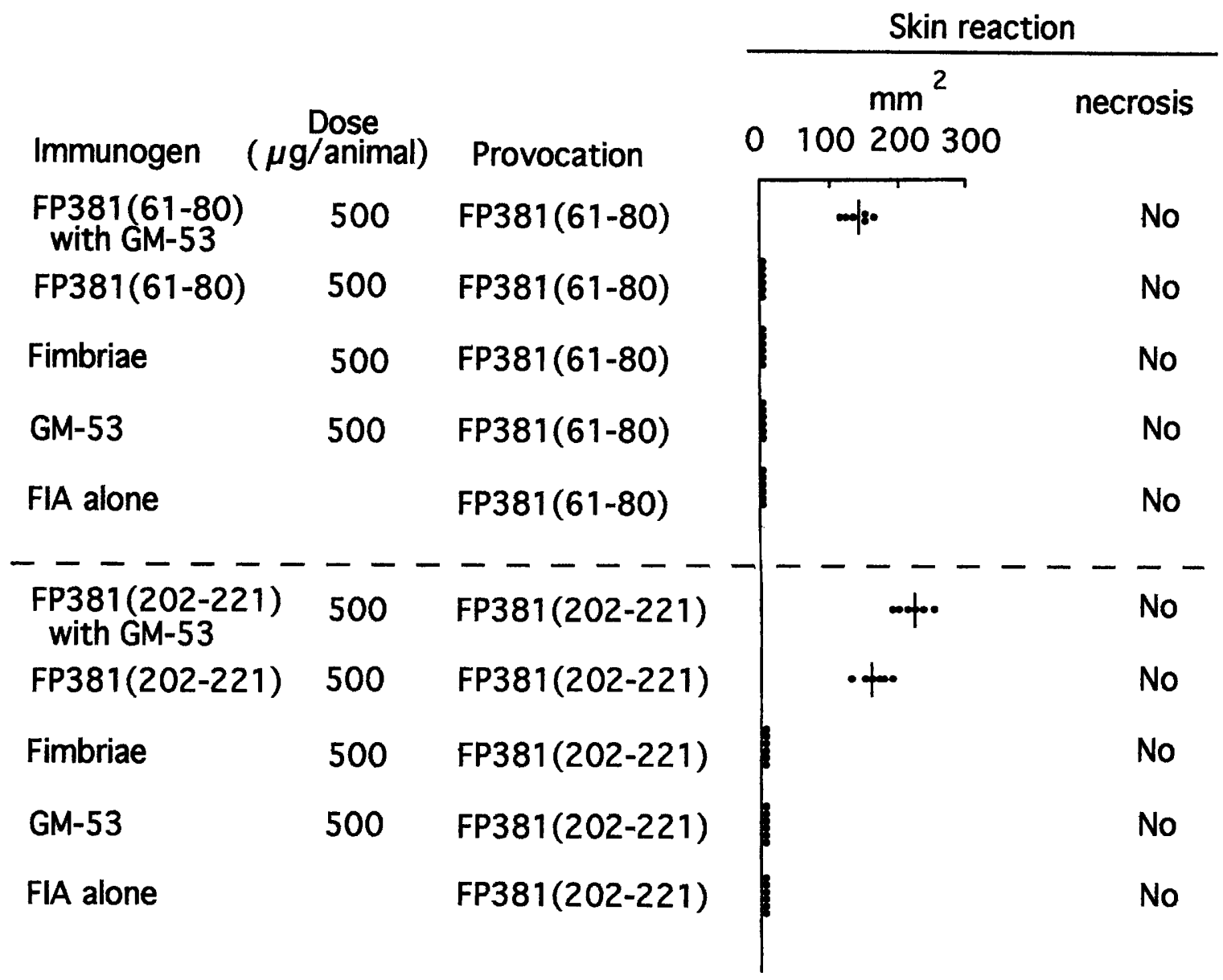

Fig. 5. Cellular immune responses induced by $P$. gingivalis fimbriae and their synthetic peptide segments in guinea-pigs. Five groups of six guinea-pigs were immunised subcutaneously with the indicated dose of $P$. gingivalis fimbriae or their synthetic peptide segments with or without $500 \mu \mathrm{g}$ of GM-53 in FIA, with GM-53 in FIA, or with FIA alone on day 0. Skin reaction was determined 35 days after immunisation. The individual values are expressed as points and the bar indicates the median value.

Table. Adjuvant activities of $P$. gingivalis fimbriae and their synthetic peptide

\begin{tabular}{|c|c|c|c|}
\hline \multirow[t]{2}{*}{ Adjuvant } & \multirow[t]{2}{*}{ Immunogen } & \multicolumn{2}{|c|}{$\begin{array}{l}\text { Mean (SE) serum anti-BSA IgG } \\
\text { concentration }(\mathrm{mg} / \mathrm{ml}) \text { after } \\
\text { injection of BSA with }\end{array}$} \\
\hline & & PBS & FIA \\
\hline Fimbriae & BSA & $0.14(0.01) \dagger$ & $15 \cdot 2(1 \cdot 1) \dagger$ \\
\hline FP381(61-80) & BSA & $0.10(0.02) \dagger$ & $12 \cdot 2(1.0) \dagger$ \\
\hline MDP & BSA & $1.73(0.28) \dagger$ & $10.8(0.8)^{*}$ \\
\hline None & BSA & $0.01(0.003)$ & $6 \cdot 1(0 \cdot 4)$ \\
\hline None & None & $0(0)$ & $0(0)$ \\
\hline
\end{tabular}

MDP, muramyldipeptide. Statistical difference from the values of the group given BSA alone at ${ }^{*} p \leqslant 0.05$ and $\dagger p \leqslant 0.01$, respectively.

FIA. The adjuvant activity of MDP in PBS was significantly greater than that of the fimbriae $(p<$ $0 \cdot 0001$ ) but fimbriae in FIA showed more adjuvancy than MDP in FIA $(\mathrm{p}<0.005)$.

\section{Discussion}

$P$. gingivalis cell surface antigens have been found to exhibit strong immune responses in man and animals. Enhanced levels of antibodies specific for these anti- gens have been detected in the serum and crevicular fluid of patients with chronic periodontal diseases. ${ }^{2-6}$ Recently, we have found that the number of $P$. gingivalis fimbriae-specific antibody producing cells were increased markedly in the gingival tissues of patients with advanced adult periodontitis. ${ }^{9}$ We have also reported that raised levels of anti-fimbrial antibodies in serum and saliva and increased numbers of antigen-specific antibody-producing cells in various tissues were observed in BALB/c mice immunised subcutaneously or orally with $P$. gingivalis fimbriae in FIA or liposomes. ${ }^{10,11,17}$ In this study, a cellular as well as a humoral immune response to $P$. gingivalis fimbriae occurred in guinea-pigs and BALB/c mice given the fimbriae with or without a semi-synthetic adjuvant GM-53 in FIA by subcutaneous injection.

Subcutaneous injection of $P$. gingivalis fimbriae together with FIA significantly raised the levels of anti-fimbrial IgG in serum and induced a marked ear lobe reaction to a provocative challenge in $\mathrm{BALB} / \mathrm{c}$ but not in BALB/c $n u / n u$ mice. However, administration of a protein antigen, BSA or ovalbumin (OA), did not result in a significant ear lobe reaction in $\mathrm{BALB} / \mathrm{c}$ mice immunised with BSA or OA in FIA (data not shown). These results revealed that $P$. gingivalis fimbriae induce cellular as well as humoral 
immune responses, and we suggest that this antigenicity depends on the $T$ cells of BALB/c mice.

Our previous studies indicated that chemically synthesised oligopeptide segments of the fimbrial subunit protein (fimbrilin) of $P$. gingivalis strain 381 exhibited a variety of immunobiological activities such as agglutination of rabbit erythrocytes, mitogenicity and PBA activities and induction of cytokines in human monocyte-macrophage cultures. ${ }^{12}$ From amongst these synthetic peptides we selected two peptide segments: FP381(202-221), which was one of the immunodominant epitopes of the fimbrial protein as shown by its inhibition of the ELISA reaction for rabbit $\mathrm{IgG}$ specific for $P$. gingivalis fimbriae, and FP381(61-80) that agglutinated rabbit erythrocytes, was mitogenic and caused PBA of BALB/c splenocytes. These peptides were found to induce cytokines such as TNF- $\alpha$ and IL-6 production in human monocyte-macrophage cultures. ${ }^{12}$ ELISA reaction revealed that levels of FP381(202-221)- but not FP381(61-80)-specific IgG were elevated in serum from guinea-pigs which had been immunised with $P$. gingivalis fimbriae (fig. 4). Fimbriae also reacted with serum from guinea-pigs immunised with FP381(202221). Furthermore, FP381(61-80) and FP381(202221) were themselves antigenic for guinea-pigs. How-

\section{References}

1. Slots J, Genco RJ. Black-pigmented Bacteroides species, Capnocytophaga species, and Actinobacillus actinomycetemcomitans in human periodontal disease: virulence factors in colonization, survival, and tissue destruction. $J$ Dent Res 1984; 63: 412-421.

2. Mouton C, Hammond PG, Slots J, Genco RJ. Serum antibodies to oral Bacteroides asaccharolyticus (Bacteroides gingivalis) relationship to age and periodontal disease. Infect Immun 1981 ; 31 : 182-192.

3. Tew JG, Marshall DR, Burmeister JA, Ranney RR. Relationship between gingival crevicular fluid and serum antibody titers in young adults with generalized and localized periodontitis. Infect Immun 1985; 49: 487-493.

4. Gmür R, Hrodek K, Saxer UP, Guggenheim B. Double-blind analysis of the relation between adult periodontitis and systemic host response to suspected periodontal pathogens. Infect Immun 1986; 52: 768-776.

5. Naito Y, Okuda K, Takazoe I. Detection of specific antibody in adult human periodontitis sera to surface antigens of Bacteroides gingivalis. Infect Immun 1987; 55: 832-834.

6. Ogawa T, Kusumoto Y, Hamada S, McGhee JR, Kiyono H Bacteroides gingivalis-specific serum IgG and IgA subclass antibodies in periodontal diseases. Clin Exp Immunol 1990; 82: $318-325$.

7. Slots J, Gibbons RJ. Attachment of Bacteroides melaninogenicus subsp. asaccharolyticus to oral surfaces and its possible role in colonization of the mouth and of periodontal pockets. Infect Immun 1978; 19: 254-264.

8. Okuda K, Slots J, Genco RJ. Bacteroides gingivalis, Bacteroides asaccharolyticus and Bacteroides melaninogenicus subspecies: cell surface morphology and adherence to erythrocytes and human buccal epithelial cells. Curr Microbiol $1981 ; 6: 7-12$ ever, these peptides did not elicit a positive skin reaction in guinea-pigs immunised with the fimbrial antigen, whereas immunisation with FP381(61-80) only led to a skin reaction when given together with GM-53 (fig. 5). FP381(202-221) induced a positive skin reaction when injected with or without GM-53. These results suggest that FP381(202-221) is the segment that contains an important antigenic epitope and is capable of inducing humoral immune response to $P$. gingivalis without showing other activities.

FP381(61-80) was shown to exhibit enough adjuvanticity to stimulate a humoral immune response to BSA in BALB/c mice when injected with BSA and FP381(61-80) in PBS or FIA (table). The ability of FP381(61-80) to exert this adjuvant effect was comparable to that of a synthetic adjuvant, MDP. The powerful antigenicity of $P$. gingivalis fimbriae may be attributed to adjuvant-active region(s) within the fimbrial molecules. Finally, a semi-synthetic adjuvant GM-53 was shown to stimulate potently both humoral and cellular immune responses to $P$. gingivalis fimbriae and their synthetic peptide antigens in this study, indicating that synthetic peptides such as FP381(202221) conjugated with GM-53 or FP381(61-80) as an adjuvant may be useful as suitable vaccine candidates against $P$. gingivalis infection.

9. Ogawa T, Kono Y, McGhee ML et al. Porphyromonas gingivalis-specific serum IgG and IgA antibodies originate from immunoglobulin-secreting cells in inflamed gingiva. Clin Exp Immunol 1991; 83: 237-244.

10. Ogawa T, Shimauchi H, Hamada S. Mucosal and systemic immune responses in BALB/c mice to Bacteroides gingivalis fimbriae administered orally. Infect Immun 1989; 57: 3466-3471

11. Ogawa T, Kusumoto $Y$, Kiyono $H$, McGhee JR, Hamada S. Occurrence of antigen-specific B cells following oral or parenteral immunization with Porphyromonas gingivalis fimbriae. Int Immunol 1992; 4: 1003-1010.

12. Ogawa $T$, Kusumoto $Y$, Uchida $H$, Nagashima $S$, Ogo $H$, Hamada S. Immunobiological activities of synthetic peptide segments of fimbrial protein from Porphyromonas gingivalis. Biochem Biophys Res Commun 1991; 180: 1335-1341.

13. Dickinson DP, Kubiniec MA, Yoshimura F, Genco RJ. Molecular cloning and sequencing of the gene encoding the fimbrial subunit protein of Bacteroides gingivalis. $J$ Bacteriol $1988 ; 170$ : $1658-1665$.

14. Merrifield RB. Solid phase peptide synthesis. I. The synthesis of a tetrapeptide. J Am Chem Soc 1963; 85: 2149-2154.

15. Furuta R, Kawata S, Naruto S, Minami A, Kotani S. Synthesis and biological activities of $N$-acetylglycosaminyl- $\beta-(1 \rightarrow$ 4)- $N$-acetylmuramyl tri- and tetra-peptide derivatives. Agric Biol Chem 1986; 50: 2561-2572.

16. Kotani S, Narita T, Stewart-Tull DES et al. Immunoadjuvant activities of cell walls and their water-soluble fractions prepared from various gram-positive bacteria. Biken $J$ 1975; 18 : 77-92.

17. Kusumoto $Y$, Ogawa T, Hamada S. Generation of specific antibody-secreting cells in salivary glands of BALB/c mice following parenteral or oral immunization with Porphyromonas gingivalis fimbriae. Arch Oral Biol 1993; 38: 361-367. 